\section{A classification of teacher interventions in mathematics teaching}

\author{
Dominik Leiß, Kassel (Germany) \\ Bernd Wiegand, Kassel (Germany)
}

\begin{abstract}
One of the best-known quotes in pedagogical literature is Maria Montessoris "Help me to do it myself." This citation can be applied to many open questions. For example, how to help students working autonomously on cognitively demanding tasks is not only an unanswered question in didactical literature, but there has also been relatively little research done in this area.

This article reflects upon qualitatively oriented studies from the German research project DISUM and selected literature about "teacher interventions". Based on this, we propose, from a mathematically didactic point of view, a multi-dimensional framework, which allows us to identify central aspects of teacher interventions.
\end{abstract}

Kurzreferat: Einer der wohl bekanntesten Sätze Maria Montessoris „Hilf mir es selbst zu tun“ wirft auch heute, Jahrzehnte später, noch zahlreiche didaktische Fragen auf. So ist in der mathematikdidaktischen Forschung bisher die Frage wie man Schülerinnen und Schüler in ihrem selbständigkeitsorientierten Lösungsprozess insbesondere bei kognitiv anspruchsvollen Aufgaben adäquat unterstützen kann nicht nur unbeantwortet geblieben sondern auch nahezu unerforscht. Der Artikel versucht unter Berücksichtigung von qualitativen Laborstudien aus dem aktuellen DFG-Forschungsprojekt DISUM $^{1}$ und unter Heranziehung ausgewählter Literatur zum Thema „teacher interventions“ $\mathrm{zu}$ einer eigenen, mathematikdidaktisch geprägten Typisierung von Lehrerinterventionen zu gelangen.

\section{ZDM-Classification: D50, M10}

\section{Educational Scenery}

The most important activity for students in the mathematics classroom is working on tasks (Christiansen \& Walter, 1986). Consequently, the selection, design, handling, and assessment of tasks are the most important responsibilities of teachers. Thus it is not surprising that in the current reform projects in Germany, which aim at raising the quality of mathematics education, a "new culture of tasks" was implemented (for SINUS see Blum et al. 2000). In this context, the following two questions are the key elements:

- "what" (integration of competence oriented tasks)

- and "how" (more cognitive activities of students in the learning process, variation of methods, ...)

In this article, we will focus on the second aspect and, more specifically, on the still unanswered questions about appropriate teacher interventions during the course of students' independence-oriented solution processes. As a first step we will propose a classification for teacher interventions in mathematics teaching. Teacher interventions are one of the focuses of the interdisciplinary German research project DISUM ${ }^{1}$ at the University of Kassel (Mathematics Education: Werner Blum / Pedagogy: Rudolf Messner / Psychology: Reinhard Pekrun, University of Munich). It aims at developing and investigating corresponding instructional concepts based on an intensive analysis of students' learning processes and on the expertise of experienced SINUS teachers (Blum \& Leiss, 2003). The subject of the research is $9^{\text {th }}$ grade math classes taught with the use of modelling tasks in schools of all types. Surprisingly, and in sharp contrast to its practical relevance, there are only a few research projects that examine the theory and practice of teacher interventions. The existing theories usually try to describe the process of mathematical problem solving from a student's point of view (or parts of it, see Polya 1967, Pollak 1979 or Reusser 1996). However, they all refer to somehow idealised linear or cyclic solving processes. It is an open question if, and if so, how far these models are appropriate for describing real solution processes, without considering interpersonal (fear, motivation), methodical (social form) and interactional (teacher interventions) factors which are relevant for the real learning processes.

It is a paradox that teacher interventions are - despite the consideration of them in these models - often said to be a key aspect in this context (see Aebli, 1994 / Dubs, 1995 / Vollrath, 2001 / Even \& Tirosh, 2002). According to this, the research done in this field is usually not very problem-specific or related to a specific subject matter like mathematics. Fürst summarizes the state of the art as follows:

„teacher intervention in group work is not often addressed in literature" and a bit later: "the phenomenon of teacher interventions is usually seen very globally, differential ... aspects are hardly discussed, an extensive typology doesn't exist." (1999, p. 121, translated by D. Leiss and B. Wiegand)

The aim in the following two parts we will form a basis for a new classification of teacher interventions, which will be proposed in the last part.

We start with an empirical perspective - different teachers intervening differently in a situation where two students try to solve a mathematical modelling task.

\section{Examples from the DISUM-Project for teacher interventions in student solution processes}

One central aspect of teacher interventions is when students are dealing with tasks in a cooperation process ("co-constructive solving", "collaborative learning" - see Dillenbourg, 1999). In order to investigate this teaching and learning situation in detail, we have isolate it from the school context and recreate it in the laboratory (see figure 1).

\footnotetext{
${ }^{1}$ The title of the study, supported by the German Research Foundation (DFG), is: Didaktische Interventionsformen für einen selbstständigkeitsorientierten aufgabengesteuerten Unterricht am Beispiel Mathematik.
} 
In one of the first phases, the students (S1 \& S2) were asked to work on four modelling tasks. If they were unable to handle a problem themselves, they were supposed to ask a teacher other than their "normal" teacher, who therefore would know nothing about their level of competence ${ }^{2}$. Prior to this laboratory situation, the teacher became acquainted with the task and its possible solutions. He also received a description of his role in this laboratory situation, which instructed him to intervene in the problem solving process according to Maria Montessori's principle "Help me to do it myself". In a second phase both students and the teacher were individually confronted with the video of the first phase. At specific moments of the video, an interviewer, who had observed the first phase $(\mathrm{O} / \mathrm{I})$, asked them about their behaviour.

Fig. 1 Laboratory - Working on the „filling up“ task

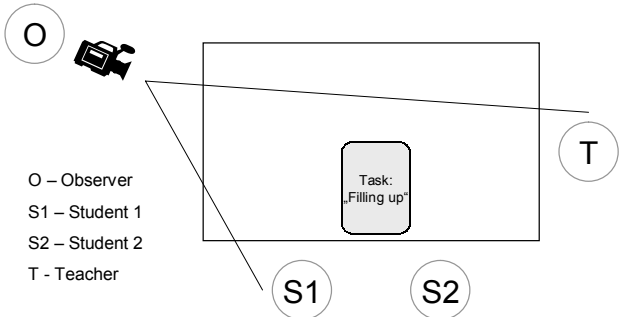

This was the last of the four tasks the students had to solve:

Filling up
Mister Stone lives in Trier close to the border of
Luxemburg. For fill up his VW Golf, he drives to
Luxemburg where immediately behind the border, which
is $20 \mathrm{~km}$ away from Trier, there is a petrol station. There
you have to pay 0.85 Euro for one litre petrol in contrast
to Trier where you have to pay 1.1 Euro.
Is it worthwhile for Mister Stone to drive to Luxemburg?

This is a modelling task (see figure 2), where one must first decide either to fill up in a place nearby or to drive a greater distance in order to pay less money for the petrol (1). One should simplify the situation, for example, by deciding not to consider costs other than the cost of driving there or not to consider the driving distance in Trier itself. Above all one has to structure the problem by the comparison of two lists of costs (2). This has to be transformed into a mathematical model - here, the difference between two terms (3) - and solved with the help of mathematical ideas (4). The result can be interpreted as saving (5) and has to be proven plausible using the situation model. Maybe this kind of validation process leads to a modification of the models used.

Even if the students fail to follow this modelling circle in the ideal way described above, one can still interpret the numbers as hints for possible difficulties of the students and, in this way, also for possible teacher interventions.

\footnotetext{
${ }^{2}$ We selected students from different levels of competency.
}

Fig. 2. Modelling circle (Blum \& Leiß, 2005)

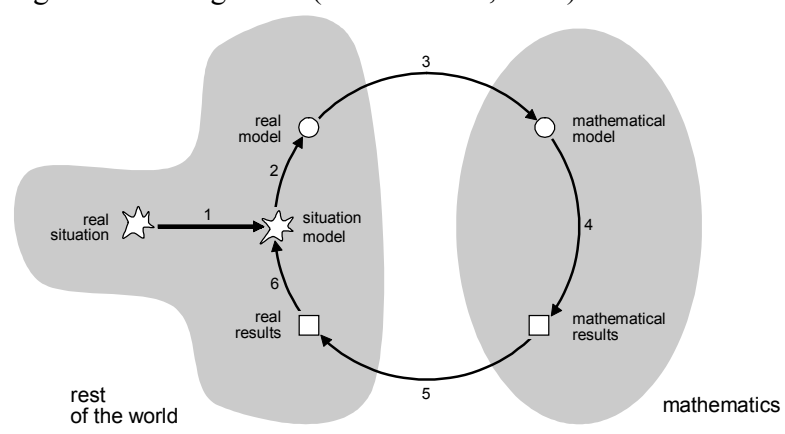

In the following passage, we will report on three of the videotaped, qualitatively oriented studies through written transcripts of the laboratory situation. Even in this limited context, the complexity of the topic of ,teacher interventions" becomes very clear.

\section{Situation 1:}

In the following sequence, the two students Daniel and Amelie (Gymnasium, middle competence) have read the task and start to work. The teacher observes the situation while sitting approximately 3/4 $\mathrm{m}$ away from the students.

D: Now we know that he lives $20 \mathrm{~km}$ away from the border.

A: May I draw a picture?

$T_{1}$ : Sure.

A: Okay this way I can make it better. So, the man lives there and this is the border to Luxemburg. And there is a petrol station.

$T_{1}$ : Very good, great.

(A creates an incorrect sketch in the following)

$D$ : And then costs a, so now we need to know what he consumes, don't we?

A: No, why? It doesn't matter.

D: Well

A: When he pays 85 cents in Luxemburg 20 times 85.

D: Ah, yes okay then we can do it. That is 18.7. So and ...

A: Hold on, what are you calculating now? It's pointless. He doesn't have to drive there at all with one Euro. That's nonsense; he doesn't have to drive to Luxemburg. It makes much more sense to divide that by the kilometres, ah, that's pointless.

D: Why? Now we have practically calculated how much one way costs.

A: Yes but ...(6 seconds silence)

$T_{1}$ : Could you think about what you want to calculate first? What is your goal?

A: We don't have a goal.

Both students try several ways, none of which leads to a solution. For example, they are not able to build an appropriate situation model, and they create an incorrect sketch. According to this, they chose the wrong way to calculate the costs of the drive to and from Luxemburg. However, there is not yet a reason for the teacher to intervene in this situation. She stays in the background and continues to observe the situation. Only at the beginning did she motivate the two students to start working. 
The teacher does not intervene until the students seem to stop working because of several mental mistakes (they jump between situation model, real model, and mathematical calculations). With her heuristic question ("what is your goal?"), it seems that she has found the students main problem, as seen in their answer, ,we don't have a goal."

\section{Situation 2:}

Christoph and Milat are two students at a relatively low competence level (Hauptschule, mark: 3-4). After having read the task aloud, they didn't say anything for about 20 seconds before the following conversation began. The teacher had his arms on the table and sat relatively close to the students (approximately $20 \mathrm{~cm}$ ).

$C$ : And now when he drives here $20 \mathrm{~km}$..

M: Yes those you need now. (1 second silence)

$T_{2}$ : When, when does he drive there to fill up?

C: $M m$, when he.

M: Well, when he doesn't have much petrol left...

$T_{2}$ : When the tank is empty, of course...

M: Yes.

$T_{2}$ : Yes. How much does he fill up then? Approximately. Two litres, four litres?

M: No

C: He'll fill up, won't he?

$T_{2}$ : Yep, he fills up, of course. Now you need to estimate, how much fits in the tank of a Golf?

M: 80 ?

$T_{2}$ : Oh, eighty, then he must have put some canisters in the trunk, I think. I don't know for sure. Well, my car takes about forty liters, it is about the size of a Golf. So he can fill up 40 litres, we'll make it easy on ourselves again. He also takes two canisters with him in the trunk so that it's worth the trip.

After reading the text, Christoph and Milat begin to talk about the real model for the way to Luxemburg. When they stop for a short while, the teacher starts a kind of ,Socratic dialogue” with them. The teacher wants to be part of the group working on the task. For example, he often has his hand on the student's piece of paper, provides different forms of assistance, sometimes in a sequenced form of questions, ...

At a first sight, this kind of content-related and guiding intervention has nothing to do with the aim of students working autonomously. However, the teacher was already aware that Christoph und Milat are students with relatively low competence. This influenced his decision to offer strong content-related help but to let them work on their own when they worked on the central calculations. In the interview, the students agreed that they felt motivated and that the teachers help was appropriate in this situation.

Whether this form of intervention is always appropriate for low-achieving students is to be debated, but it made it possible for Christoph and Milat to solve a complex task, which was not solved by any of the pairs of students without support from a teacher.

\section{Situation 3:}

The two students Kreta and Astrid (Gymnasium, mark: 34) have calculated how expensive it is for Mister Stone to drive to Luxemburg and fill up there. They want to compare this result with the cost of filling-up in Trier. The teacher remains at a distance of approximately 1 metre from the students and has her arm crossed under the table on her knees for the majority of the time.

A: Now we look at how much he would pay if he filled up at home. But we don't know how far it is from home to the petrol station. (to the teacher).

$T_{3}$ : (the hand of the teacher points at the student as answer)

A: Are we supposed to calculate this approximately? I mean it's probably not that far away? Are we supposed to estimate that now?

$T_{3}$ : (she points with her hand at the student as answer)

A: Yes?

$T_{3}$ : (she points with her hand at the student as answer)

A: Good, one kilometre? Half a kilometre? (to G.) Okay, for you its less, but for us its about $0.5 \mathrm{~km}$.

$G$ : But we can't just write that down...

A: Yeah, but were do we get it from?

$G$ : Do we need that at all (to the teacher)?

$T_{3}$ : I am asking you!

(As a result, Astrid explains to Greta why they need this detail for about $15 \mathrm{sec}$. and then abruptly interrupts her explanation with the following sentence.)

A: Oh, no we just calculate...(in the following she does her real model without the consideration of a distance between the house and the petrol station in Trier).

Both students are not used to working on tasks where one has to make assumptions on one's own. Therefore they have difficulty setting up a real model. The teacher tries to avoid offering help and often throws the ball back to the students. Later in the interview, she justified this reaction by saying that the students should first discuss the problems themselves. By doing this, it is easier for them to find a solution on their own. The sequence above shows that the teacher was successful using this sort of interaction. However, one has to consider that on one hand, it took a relatively long time for the students to get a result (twice as long as usual) and on the other hand, the students said they felt unmotivated (stimulated recall). In particular, they missed having help related to specific knowledge they didn't have (for example the fuel consumption rate).

Although having presented only some sequences of the three teachers, one can say that their behaviour is a typical representation of the way they usually intervene. In the following section, it will become clear that the forms of interventions presented above still go far beyond what one can find in the current literature related to this topic. 


\section{Teacher interventions - a brief survey of related literature}

After having presented typical teacher interventions, we will now give a summary of the literature related to this topic (listed in order of increasing complexity of the afore mentioned teacher interventions). Based on this, we will propose a multi-dimensional framework, which, in its very first step, allows for the categorization of different types of teacher interventions. The focus of our article is not to compare the different approaches or to identify "the best" strategy for intervention (if one exists), because, in our opinion, the differences between the approaches are too great. Due to space limitations, it is only possible for us to describe the essential points of every article.

- The first author we mentioned was Maria Montessori, because she did a lot of pedagogical work related to students working autonomously. A central part of Montessori's work is the so-called "prepared environment" (1), defined as special materials which have to be arranged by the teacher. These materials for example the well-known pearls or sticks - allow the students not only to work autonomously, but also to correct themselves while they work. In Montessori's opinion, one of the main tasks of the teacher is to observe the students during their working phase that's what we call diagnosis. This central element of our framework can also be seen as the prior condition of any kind of teacher intervention.

- Loska (1995) describes the "neo-Socratic" method, in which the teacher must not intervene in any way with the content of the students work. The teacher may only pose questions that can guide a conversation or discussion (2) between students in a certain direction such as "Can you explain this with an example?" or "Do you agree with ...?" In order to do this, the teacher has to understand many of the structures of the studentstudent-conversation or, in other words: The teacher has to do a lot of diagnosis before intervening.

- Dekker/Elshout-Mohr (2004) distinguish between two different types of teacher interventions: On one hand, there is "process help" (3), which means help only in the context of student-student-interactions. On the other hand, there is "product help" (4), which stands for interventions concerned with the student's mathematical reasoning and products. Two different groups of students from a similar background took part in a pretest-posttest study design, where they had to work on several tasks either under "process-help conditions" or under "product-help conditions". The study showed that process help is more effective than product help.

- In Riedel (1973), one can find a detailed description of teacher interventions in the context of "discovery learning", including an empirical study. The author distinguishes between problem- and result-oriented help. Additionally these two categories are subdivided into problem-oriented organization (5) / structurization help (6) and result-oriented organisation help (5) / help given during the solving-process (7). The empirical study showed that problem-oriented help is more effective, especially in the way that students are better able to transfer their knowledge.

- In their article, Holton/Thomas (2001) refer to the "classroom learning project", where they performed a detailed analysis of several mathematics and science lessons. Based on these lessons and on further studies, they distinguish between three different categories: metacognitive (8), cognitive (9) and affective (10) "scaffolding". This is a widely used phrase in English teacher intervention literature and basically means help or assistance. Holton and Thomas also mention the influence of the addressee of the intervention (the whole class, a group of students, or a single student) and the possible effects caused by the work phase in which the intervention took place (at the beginning, in the middle, or at the end).

- King/Staffieri/Adelgais (1998) describe a study dealing with "peer tutoring" in science. Therefore they trained three groups of students for five weeks according to different forms of tutoring: one group received training in explanation skills (11), the second one in questioning skills (12), and the third one in explanation, questioning and in the so-called question sequencing skills (13, subdivided in review, probing, hint and thinking questions). The last group, which had been trained in all three categories, obtained the best results in this study.

- Kramarski/Mevarech/Arami (2002) also refer to the "tutoring"-context. Their pretest-posttest study tries to explore the effects of "metacognitive instruction" in the form of special training for students who work in small groups on mathematical tasks by formulating and answering self-adressed questions focussed on the following points: comprehending the problem (14), constructing connections between old and new knowledge (15), using appropriate strategies (16), and reflecting on both the process and the solution (17). The study showed that the group of students instructed in this way obtained better results than a control group.

- Serrano (1996) analysed the TIMSS-Video study and found interesting cultural differences between Japan and the USA in the way teachers organize group work in mathematics lessons. In particular, she analysed how often and how they intervene. She distinguishes between the following forms of teacher interventions: tell/demonstrate (18), provide hints (19), encourage thinking (20), and evaluation only (21).

- Becker/Shimada 1997 mention four aspects that can help students effectively understand the given problem (e.g. the first phase): focus on the same issue (22), add more data for generalisations (23), give non-restricting examples (24), and use concrete materials (25).

- Chi et al. (2001) describe a "tutoring" study with many aspects related to teacher interventions. They name several forms of interventions (sequencing the task (26), direct feedback (27), giving explanations (28), answering questions (29), asking content questions $(30), \ldots)$, but in a more or less unstructured way.

- Zech (2002), based on his own experience and on other literature (for example Riedel 1973), proposes the following taxonomy of possible ways to help students solve problems: motivational help (31), feedback-help 
(32), strategic help (33), content-oriented strategic help (34), and content-related help (35) (listed in order of increasing intensity). According to this, each method of assistance can be provided directly or indirectly, for example: "Draw this line." (direct content-related help) or "Have a look at the text again." (indirect strategic help).

After having presented the main literature on teacher interventions, which had mathematics or science as a topic, we will finish this brief summary by naming some key points of the general pedagogical literature:

- Meyer (1999), one of the prominent German-speaking sources of literature on this topic, gives only general advice on how to behave as a teacher while students are working in groups. He stresses the negative impact on students' autonomous work and therefore recommends being passive and observing the students most of the time. The only exception is help related to stabilizing group work.

- Fürst (1999) gives a detailed report of an interdisciplinary research project on group work. As mentioned above, he states that not much literature related to teacher interventions exists and that a detailed classification is still not available. He himself distinguishes between two variables: the initiator (teacher or student) and the addressee of the intervention (whole group or single student). According to this, he analyses teacher interventions in group work based on four scales: the quality of the observation by the teacher, the quality of the appropriateness of the intervention, the quality of the teacher-student-conversation, and the amount of guidance provided by the teacher. The analysis of over 100 teacher interventions showed a lot of practical problems (teacher usually as the initiator, teacher has not observed well enough in advance, intervention is not adequate, negative correlation between teacher intervention and result of group work).

- Haag (2005) refers mainly to Fürst (1999) (who confirms that there is still not much research in this area) and recommends allowing the students to work primarily on their own. The teacher should be very careful when intervening. If intervention is necessary, it should mainly consist of waiting and observing and should only take place when students explicitly ask for it. It is important that teachers influence group work as little as possible when intervening.

\section{A multi-dimensional framework for teacher interventions}

By comparing the different approaches in the literature presented above, we found some similarities that allow us to identify in a first step the following four various categories of teacher interventions:

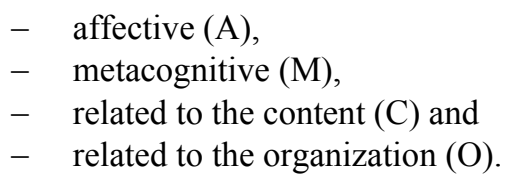

The classification of the different aspects mentioned in the literature above into the four categories of teacher interventions can be seen in the following figure:

\begin{tabular}{|c|c|c|c|c|}
\hline & $\mathbf{A}$ & $\mathbf{M}$ & C & $\mathbf{O}$ \\
\hline Montessori & & & & 1 \\
\hline Loska & & & & 2 \\
\hline Dekker ... & 3 & 4 & 4 & 3 \\
\hline Riedel & & 6 & 7 & 5 \\
\hline Holton ... & 10 & 8 & 9 & \\
\hline King ... & & $11-13$ & & \\
\hline Kramarski ... & & $14-17$ & & \\
\hline Serrano & & $20-21$ & $18-19$ & \\
\hline Becker ... & & & $23-25$ & 22 \\
\hline Chi ... & & $26-27$ & $28-30$ & \\
\hline Zech & 31 & 33 & \begin{tabular}{l|l}
34 & 35
\end{tabular} & \\
\hline
\end{tabular}

Although there are of course more relevant aspects in this context, in our opinion, however, they describe the main aspects of teacher interventions. A fifth category, which is also very important, is diagnosis, which should be the prior condition to all interventions. We believe that this fifth aspect can also be seen as an alternative to the other four forms of intervention. By choosing not to intervene, the teacher decides to continue observing the situation either to become better informed or to give the students the opportunity to find a solution on their own, like the teacher in situation $3 \mathrm{did}$. In contrast to this the teacher in the first situation intervenes in a metacognitive way, whereas the teacher in situation 2 chose the contentrelated form of intervention.

Beyond these five categories and sometimes parallel to them, we have already mentioned some other aspects that are more or less relevant in the context of teacher interventions. It is interesting that these dimensions were primarily mentioned in the general pedagogical literature, whereas the first four categories are not named there. These dimensions are, for example, the question of the initiator and the addressee, the possible dependency of the working phase, and the degree of directness. Leiß (2005) also named the possible influences of:

- the point of time in which the teacher intervenes,

- the type of problem the students work on,

- the "niveau" of the teacher intervention,

- the method of intervention chosen by the teacher.

It is no surprise that when a teacher is in front of a group of students working on a problem autonomously and has to decide whether he or she should intervene or not (and how) seems to be a very complex one. Nevertheless, it is a common situation for all teachers and happens several times a day. The proposed framework for teacher interventions is only the first, but very relevant step towards a better understanding of these situations. 


\section{References}

Aebli, H. (1994). Zwölf Grundformen des Lehrens. Stuttgart.

Becker, J.B. \& Shimada, S. (1997). The Open-Ended Appproach: A New Proposal for Teaching Mathematics. Reston.

Blum, W. \& Leiss, D. (2003). Diagnose- und Interventionsformen für einen selbstständigkeitsorientierten Unterricht am Beispiel Mathematik - Vorstellung des Projekts DISUM. - In: Beiträge zum Mathematikunterricht. Hildesheim: Franzbecker, S. $129-$ 132.

Blum, W. \& Leiss, D. (2005). Modellieren mit der "Tanken"Aufgaben. In: mathematic lehren (128), 18-21.

Blum, W., et al. (2000). Gute Unterrichtspraxis: Steigerung der Effizienz des mathematisch-naturwissenschaftlichen Unterrichts. Pro Schule 3/2000. Fuldatal.

Chi, M.T.H. et al. (2001): Learning from human tutoring. In: Cognitive Science 25, 471-533.

Christiansen, B. \& Walther, G. (1986). Task and activity. In: Christiansen, B., Howson, G. \& Otte, M. (Eds.). Perspectives on mathematics education. Dodrecht: Kluwer, S. $243-307$.

Dekker, R.; Elshout-Mohr, M. (2004): Teacher interventions aimed at mathematical level raising during collaborative learning. In: Educational Studies in Mathematics 56, 39-65. Dillenbourg, P. (1999). Collaborative Learning. Amsterdam.

Dubs, R. (1995). Lehrerverhalten. Ein Beitrag zur Interaktion von Lehrenden und Lernenden im Unterricht. Zürich.

Even, R. \& Tirosh, D. (2002). Teacher Knowledge and Understanding of Students' Mathematical Learning. In. L.D. English (Ed.), International Research in Mathematics Education, 219-240.

Fürst, C. (1999): Die Rolle der Lehrkraft im Gruppenunterricht. In: Dann, H.-D.: Gruppenunterricht im Schulalltag - Realität und Chancen. Erlangen: Univ.-Bibliothek, 107-146.

Haag, L. (2005): Gruppenmethoden und Gruppenarbeit. In: Pädagogik 3, 26-30.

Holton, D.; Thomas, G. (2001): Mathematical Interactions and Their Influence on Learning. In: Clarke, D. (Ed.): Perspectives on practice and meaning in mathematics and science classrooms. Dordrecht: Kluwer, 75-104.

King, A.; Staffieri, A.; Adelgais, A. (1998): Mutual Peer Tutoring: Effects of Structuring Tutorial Interaction to Scaffold Peer Learning. In: Journal of Educational Psychology 1, 134-152.

Kramarski, B.; Mevarech, Z.R.; Arami, M. (2002): The effects of metacognitive instruction on solving mathematical authentic tasks. In: Educational Studies in Mathematics 49, 225-250.

Leiß, D. (2005): Teacher Interventions vs. Self-regulated Learning? In: Teaching Mathematics and its Applications (in press).

Loska, R. (1995): Lehren ohne Belehrung: Leonard Nelsons neosokratische Methode der Gesprächsführung. Bad Heilbrunn: Klinkhardt.

Ludwig, H. (2004): Montessori-Schulen und ihre Didaktik. Baltmannsweiler: Schneider Verlag Hohengehren.

Meyer, H. (1999): UnterrichtsMethoden. Teil II: Praxisband. Frankfurt am Main: Cornelsen Scriptor, 238-270.

Pollak, H.O. (1979). The interaction between mathematics and other school subjects. New trends in mathematics teaching. The international commission on mathematical instruction (Vol. IV, pp. 232-248). Paris.

Polya, G. (1962, 1965). Mathematical Discovery: On Understanding, Learning, and Teaching Problem Solving, Vol. I and Vol. II. New York.

Reusser, K. (1996). From Cognitive Modelling to the Design of Pedagogical Tools. International Perspectives on the Design of Technology-Supported Learning Environments. S. Vosniadou, E. De Corte, R. Glaser and H. Mandl (Eds.).

Riedel, K. (1973): Lehrhilfen zum entdeckenden Lernen. Hannover.
Serrano, A. M. (1996). Opportunities for online assessment during mathematics classroom Instruction. Los Angeles (Dissertation).

Vollrath, H.J. (2001). Grundlagen des Mathematikunterrichts in der Sekundarstufe. Heidelberg.

Zech, F. (2002): Grundkurs Mathematikdidaktik. Weinheim, 307368.

\section{Authors}

Leiß, Dominik, University of Kassel, FB 17, Heinrich-PlettStraße 40, 34132 Kassel, Germany

Email: dleiss@mathematik.uni-kassel.de

Wiegand, Bernd, University of Kassel, FB 17, Heinrich-PlettStraße 40, 34132 Kassel, Germany 